\title{
Assessing the role of deep rooted vegetation in the climate system with model simulations: mechanism, comparison to observations and implications for Amazonian deforestation
}

Received: 4 February 1998 / Accepted: 15 June 1999

\begin{abstract}
Deep rooted vegetation (of up to $68 \mathrm{~m}$ ) has been found in many parts of the tropics. However, models of the general atmospheric circulation (GCMs) typically use rooting depths of less than $2 \mathrm{~m}$ in their land surface parametrizations. How does the incorporation of deep roots into such a model affect the simulated climate? We assess this question by using a GCM and find that deeper roots lead to a pronounced seasonal response. During the dry season, evapotranspiration and the associated latent heat flux are considerably increased over large regions leading to a cooling of up to $8 \mathrm{~K}$. The enhanced atmospheric moisture is transported towards the main convection areas in the inner tropical convergence zone where it supplies more energy to convection thus intensifying the tropical circulation patterns. Comparison to different kinds of data reveals that the simulation with deeper roots is much closer to observations. The inclusion of deep roots also leads to a general increased climatic sensitivity to rooting depth change. We investigate this aspect in the context of the climatic effects of large-scale deforestation in Amazonia. Most of the regional and remote changes can be attributed to the removal of deep roots. We conclude that deep rooted vegetation is an important part of the tropical climate system. Without the consideration of deep roots, the present-day surface climate cannot adequately be simulated.
\end{abstract}

\footnotetext{
A. Kleidon $(\bowtie)^{1} \cdot$ M. Heimann ${ }^{2}$

Max-Planck-Institut für Meteorologie,

Bundesstraße 55, 20146 Hamburg, Germany

E-mail: akleidon@leland.stanford.edu

Present addresses:

${ }^{1}$ Department of Biological Sciences,

Stanford University, Stanford, CA 94305, USA

${ }^{2}$ Max-Planck-Institut für Biogeochemie,

Postfach 1001 64, 07701 Jena, Germany
}

\section{Introduction}

Land surfaces are distinctively different to oceans in that water is not abundantly available for evapotranspiration but limited by precipitation input and water storage in the soil. Only in the presence of vegetation with a welldeveloped root system can considerable amounts of water be extracted from the soil and transpired back into the atmosphere. This soil storage of plant-available water becomes increasingly important with greater seasonality in precipitation. Thus, the extent of the rooting zone, or rooting depth, is an important vegetation parameter in land surface parametrizations in regions with a seasonal climate. This is confirmed by observations, e.g. by Nepstad et al. (1994) who found that an evergreen forest at the margin of the Amazon basin developed deep roots of up to $18 \mathrm{~m}$ and consequently was capable of transpiring considerable amounts of water throughout the dry season. From the greenness of the vegetation observed by satellites and the seasonality of precipitation they estimated that the deep-rootedness of the vegetation could be common to large parts of the Amazon basin. Evidence for deep rooted vegetation has also been reported from many other regions (see e.g. Stone and Kalisz 1991; Canadell et al. 1996) with similar impacts on the hydrological cycle (e.g. Edwards 1979).

However, land surface parametrizations in general circulation models (GCMs) of the atmosphere generally use values of less than $2 \mathrm{~m}$ for rooting depth (e.g. BATS, Dickinson et al. 1993; SiB, Sellers et al. 1996; ECHAM, Roeckner et al. 1996). This is in contrast to the evidence from observations. Consequently, the model simulations likely contain errors in the computation of dry-season evapotranspiration and the associated heat fluxes, but also in the climatic sensitivity to rooting depth. The importance of evapotranspiration from the land surface for the climate system has been pointed out before, for instance, by the sensitivity studies conducted by Shukla and Mintz (1982) and Milly and Dunne (1994). 
How can a reasonable rooting depth distribution be obtained which takes explicit account of the deep roots found in many regions of the tropics? On the one hand, observations of rooting depth are only sparsely available, and on the other hand, the hydrological significance of the reported values is not clear. Instead of using a distribution assembled from observations, we take a different approach (Kleidon and Heimann 1998a). We compute a distribution using an optimization principle in which we maximize the long-term mean of the net primary production (NPP) in respect to rooting depth. In this approach, NPP serves as a measure of the vegetation's benefit or "fitness" (Schulze 1982) and the method can be seen as an implementation of the evolutionary principle in which vegetation makes best use of its environment. We applied this method to a simple biosphere model (which calculates NPP) embedded into a GCM and found that the obtained rooting depths were reasonable, much larger than those used in the standard model and had a considerable impact on the simulated climate, mainly in the tropics (Kleidon and Heimann 1998b).

The aim of the work presented here is to understand in more detail the mechanism by which deep rooted vegetation affects the tropical climate system and the climatic consequences of its removal, for instance by land use change. We use the ECHAM 4 GCM in order to isolate this mechanism. Our methodology is described in more detail in the following section. In Sect. 3 we compare the model simulation which includes deep roots to the one with the standard rooting depth distribution and describe the mechanism involved. By conducting a comparison to observations we assess whether the incorporation of deep roots leads to an overall improvement in the climate model's performance (Sect. 4). The mechanism described here has direct implications for the climatic effects of large-scale land use change. In Sect. 5 we conduct additional model simulations to quantify the role of deep root removal in relation to other land surface parameter changes in the context of large-scale Amazonian deforestation. Our findings are discussed and compared to other studies in Sect. 6. We close with a brief summary and conclusion in Sect. 7.

\section{Methods}

In this study, we use the ECHAM 4 general circulation model (Roeckner et al. 1996) in its T21 resolution $\left(\approx 5.6^{\circ}\right.$ latitude $* 5.6^{\circ}$ longitude). This model simulates the general circulation of the atmosphere by solving the equations of motion in spectral space. In the following we concentrate on the description of the land surface in this model and on the method which we used to derive the distribution of rooting depth.

\subsection{Description of the land surface parametrization}

The land surface of the model is characterized by a set of surface parameters, which include albedo, fraction of vegetation cover, leaf area index (LAI), total roughness length (i.e. the composite of both, roughness from orography and vegetation cover), forest fraction, a heterogeneity parameter for runoff computation (see later) and soil water storage capacity. Total evapotranspiration over land is the sum of four fractions: evaporation from snow, from the skin reservoir (i.e. re-evaporation of intercepted water from the canopy, with the canopy storage capacity depending on the leaf area index), from bare soil and from transpiration. Transpiration occurs from the part of the grid cell, which is not covered by snow and where no water is stored in the skin reservoir.

Transpiration $(E T)$ is calculated by using the bulk transfer method:

$E T=\rho C_{H}\left|v_{H}\right| \beta\left(q_{S}-q_{A}\right)$

Here, $\rho$ is the density of air, $C_{H}$ the bulk transfer (or drag) coefficient of latent heat, $v_{H}$ the horizontal wind speed, $q_{S}$ the specific humidity at saturation under the surface conditions (specified by surface temperature $T_{S}$ and pressure $p_{S}$ ), and $q_{A}$ the specific humidity at an atmospheric reference level. The parameter $\beta$ describes the decrease of transpiration as a response to water stress and is determined by

$\beta=\left[1+\frac{C_{H}\left|v_{H}\right| r_{C}}{\alpha(D)}\right]^{-1}$.

The stomatal resistance $r_{C}$ of the canopy is parametrized by an empirical function, depending on photosynthetically active radiation $P A R$ (taken as $55 \%$ of net shortwave radiation at the surface) and leaf area index, based on Sellers et al. (1986).

The water stress factor $\alpha$ depends on soil moisture and, indirectly, on rooting depth $D$ :

$\alpha(D)= \begin{cases}1 & ; W_{C R} \leq W \\ \frac{W-W_{P W P}(D)}{W_{C R}(D)-W_{P W P}(D)} & ; W_{P W P} \leq W \leq W_{C R} \\ 0 & ; W \leq W_{P W P} .\end{cases}$

Here, $W$ is the amount of water stored in the rooting zone of the soil, $W_{P W P}$ is the soil water content at the permanent wilting point $P W P$ (set to $35 \% W_{M A X}$ in the model), $W_{C R}$ is the critical soil water content at which transpiration is reduced (set to $75 \% W_{M A X}$ in the model), and $W_{M A X}$ is the maximum soil water content, depending on the rooting depth $D$ :

$W_{M A X}(D)=D \times F C$

$F C$ is the field capacity of the soil, expressed as the amount of water stored per meter depth of soil.

Soil hydrology is simulated with a budget equation (similar to the "bucket" model). It includes a sophisticated computation of surface runoff (Dümenil and Todini 1992) which accounts for subgrid scale heterogeneity of the terrain height. Also, an explicit formulation for slow and fast drainage is used, depending on the water content of the rooting zone $W$.

We decided to use the distribution of plant available water $P A W$, that is, FC-PWP , of Batjes (1996) instead of the distribution of field capacities used in the standard model of Patterson (1990) in order to determine the soil water storage size for a given distribution of rooting depth (according to Eq. 4). This is motivated by the general overestimation of $P A W$ values when a parametrization for temperate soils is used for tropical soils which usually have a very high clay content due to the advanced stage of weathering (e.g. Chauvel et al. 1991; Hodnett et al. 1995; Tomasella and Hodnett 1996). In the data set of Batjes (1996), these low values are explicitly considered. Batjes (1996) only gives ranges of $P A W$. We assign the mean value to each category except for the categories 0-60 $\mathrm{mm}$ (where we use $40 \mathrm{~mm} / \mathrm{m}$ ) and $>150 \mathrm{~mm} / \mathrm{m}$ (where we use $200 \mathrm{~mm} / \mathrm{m}$ ) (Batjes personal communication). Field capacities were then derived by

$F C=\frac{P A W}{1-0.35}$

following the definition of $P W P$ within the model.

\subsection{Determination of deep roots}

Deep roots are incorporated into the model by using optimized rooting depths which are taken from Kleidon and Heimann 
(1998b). These rooting depths were obtained by maximization of long-term mean of net primary production. To do so, an explicit formulation of instantaneous productivity $(N P P)$ was incorporated into the model, based on a simple parametrization depending on solar radiation and water stress (Monsi and Saeki 1953; Monteith 1977; Heimann and Keeling 1989):

$N P P=A \cdot \alpha \cdot P A R$.

The formulation of water stress given by Eq. (3) was used for $\alpha$ and $55 \%$ of the net solar radiation at the surface for the photosynthetically active radiation $P A R$. The model was run for six years, with the first year discarded to avoid spin up effects, and the mean of NPP over the last five years of the simulation was taken as a representative of the long term mean. The maximization was then conducted iteratively by "Golden Section Search" (Press et al. 1992). Within each iteration, the model was run again for six years in order to compute the long term mean of $N P P$ for a new distribution of adjusted rooting depth.

The rooting depths obtained from the optimization are considerably larger than those in the standard version and agree well with observations by Canadell et al. (1996) and those derived from satellite observed greenness (Knorr 1997).

\subsection{Setup of the simulations}

We conduct two model simulations in order to investigate the effect of deep rooted vegetation:

1. In the "standard" simulation, we use the standard distribution of rooting depth and the associated size of the soil water storage capacity of the rooting zone $W_{M A X}$ which is taken from Patterson (1990). In this distribution, rooting depths are generally less than $2 \mathrm{~m}$, depending on the biome type.

2. In the "deep roots" simulation, we use the optimized rooting depths. Since consistent increases in evapotranspiration, resulting from the use of optimized rooting depths, were found mainly in the tropics, we incorporate optimized rooting depths only in the tropics, that is, between $30^{\circ} \mathrm{N}-30^{\circ} \mathrm{S}$. The soil water storage capacities are left unchanged in the extratropics. The resulting distribution of rooting depth is shown in Fig. 1.

All other surface parameters such as albedo, roughness length and vegetation cover are left unchanged. The two simulations are initialized with the same soil wetness (i.e., actual divided by maximum soil water content) and are conducted for 20 years. Sea surface temperatures are prescribed to their climatological values. In order to exclude spin-up effects, the first five years are discarded in the

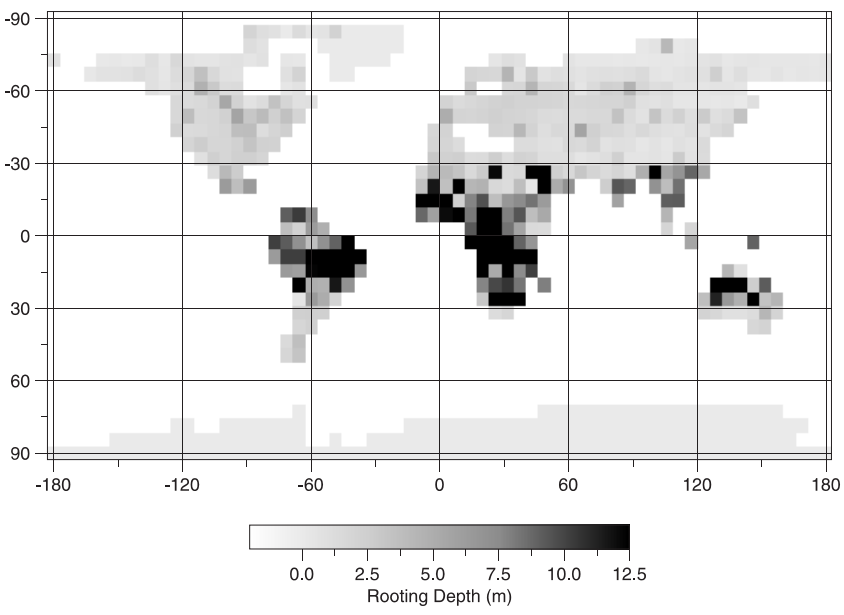

Fig. 1 Distribution of rooting depths used in the "deep roots" simulation. Rooting depths exceed $2 \mathrm{~m}$ in the extratropics because a different soil texture data set is used than in the standard version of the model evaluation. The significance of the changes between the two simulations is estimated with the student's $t$-test (with $P \leq 0.05$ ). The comparison is focused on seasonal averages from December to February ("DJF", which is roughly the dry/wet season in the northern/southern tropics) and June to August ("JJA", which is roughly the wet/dry season in the northern/southern tropics).

\section{Atmospheric effects of deep rooted vegetation}

The atmospheric changes resulting from the incorporation of deep roots (compared to the standard simulation) can be understood by the mechanism shown in Fig. 2. In the following, we will first follow the diagram step by step and show the difference between the corresponding variables of the two simulations in Figs. 3, 4 before we describe the feedback processes involved.

\subsection{Direct changes}

The increase in rooting depth (associated with the incorporation of deep roots) leads to an increase in plant-available soil water storage capacity which then increases dry-season evapotranspiration (as long as evapotranspiration is limited by water storage). A largescale increase in evapotranspiration takes place on the dry season hemispheres (Fig. 3A, B). During DJF, the increases are concentrated over northern South America, Africa, and India/Southeast Asia, while small decreases are found over some parts of southern tropical South America, southern tropical Africa and Australia. This picture consistently changes during JJA, where the

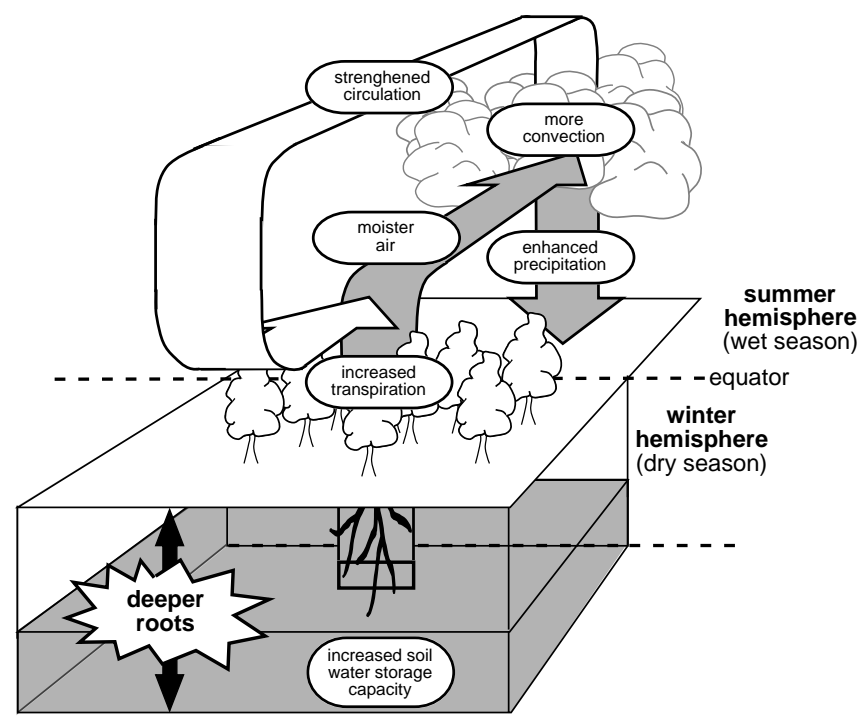

Fig. 2 This figure illustrates the effect of deep rooted vegetation (increased rooting depth) on the atmosphere. Deep roots provide an increased soil water storage capacity which increases the access to water stored in the soil for dry periods. Consequently, transpiration is generally enhanced during the dry season leading to local cooling and moister air. This way, more moisture (and energy) is transported to the inner tropical convergence zone resulting in enhanced precipitation on the other hemisphere and a generally strengthened circulation. The shaded areas denote water 


\section{December-February}

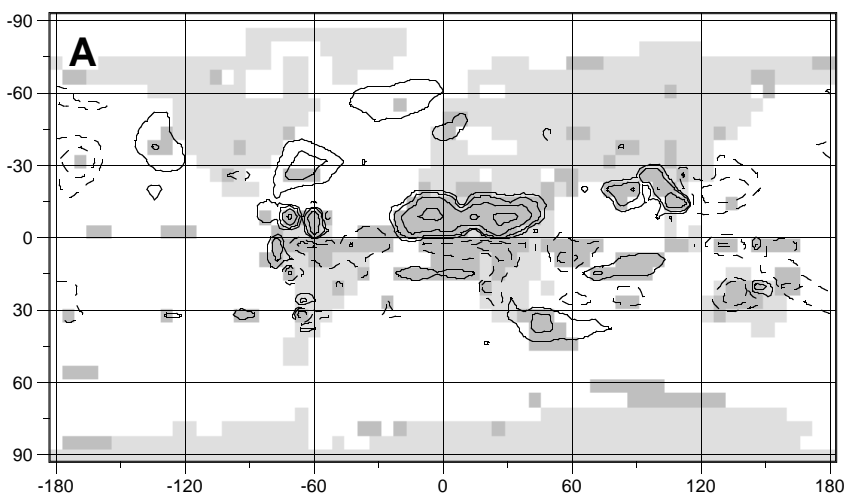

June-August

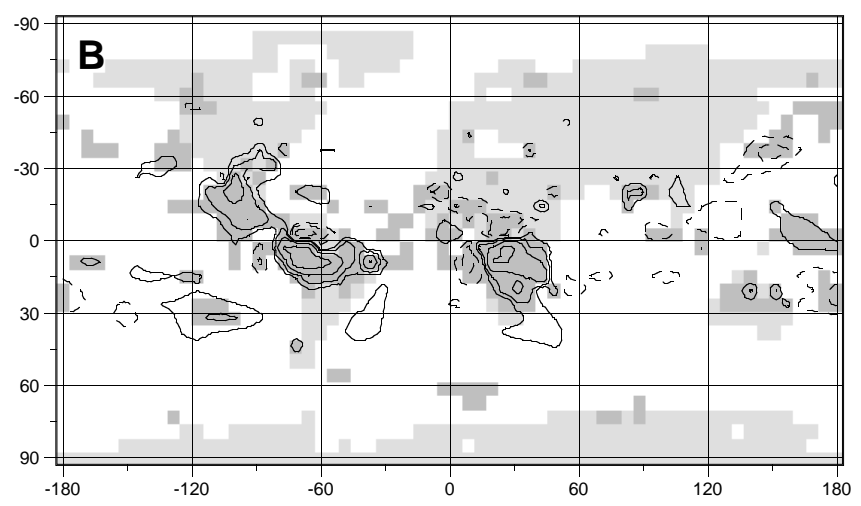

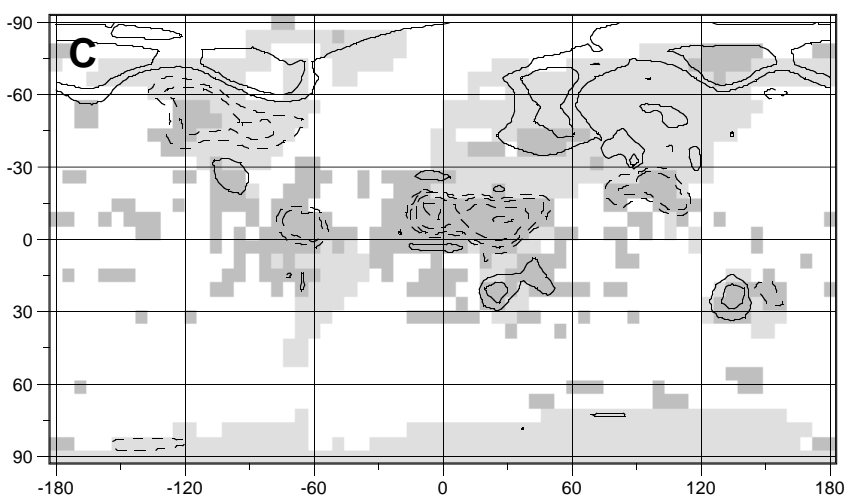

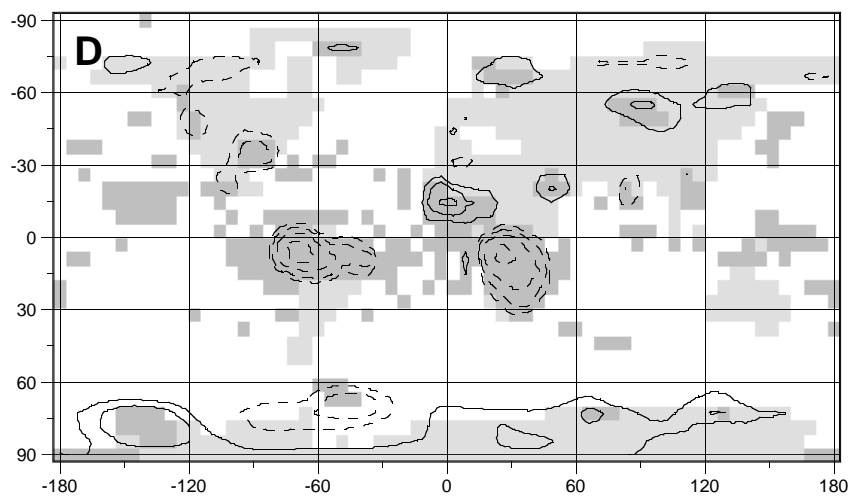

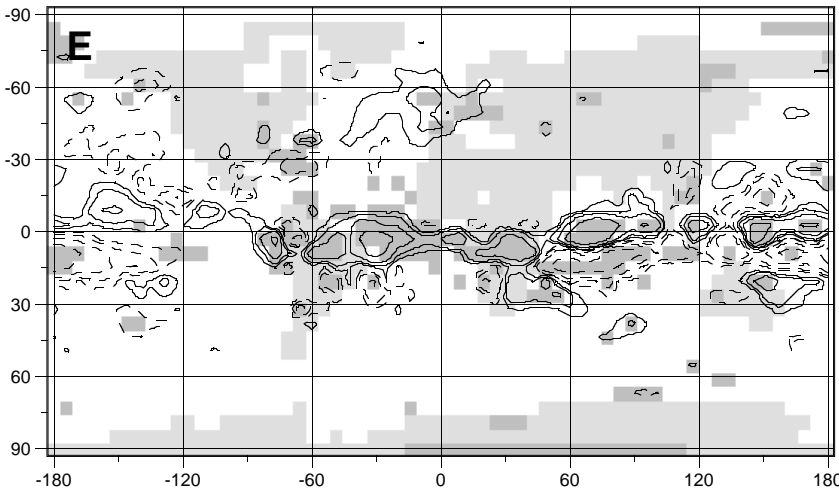

Fig. 3A-F Mean seasonal changes in A, B evapotranspiration, C, D $2 \mathrm{~m}$ air temperature, and $\mathbf{E}, \mathbf{F}$ precipitation for the DecemberFebruary (left) and June-August (right) season respectively. Solid (dashed) contour lines denote positive (negative) changes. Significant

increases in evapotranspiration occur over southern tropical South America and southern tropical Africa. A decrease in evapotranspiration is found over northern Africa. In addition, a large-scale increase in evapotranspiration occurs over the eastern tropical Pacific and

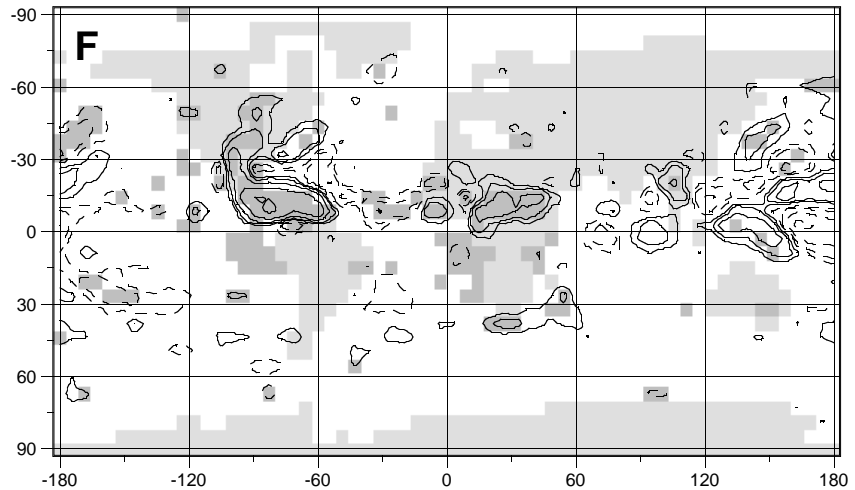

changes are shown by gray (student's $t$-test, $P \leq 0.05$ ). Contours are at $\pm 4,2,1,0.5,0.25 \mathrm{~mm}$ /day for water fluxes and $\pm 4,2,1,0.5 \mathrm{~K}$ for air temperature. Light gray areas indicate land region in which no significant changes take place

Mesoamerica as a result of increased precipitation (see later).

The enhanced latent heat flux associated with the increases in evapotranspiration leads to a cooling of the surface. Consequently, considerable decreases in near 


\section{December-February}

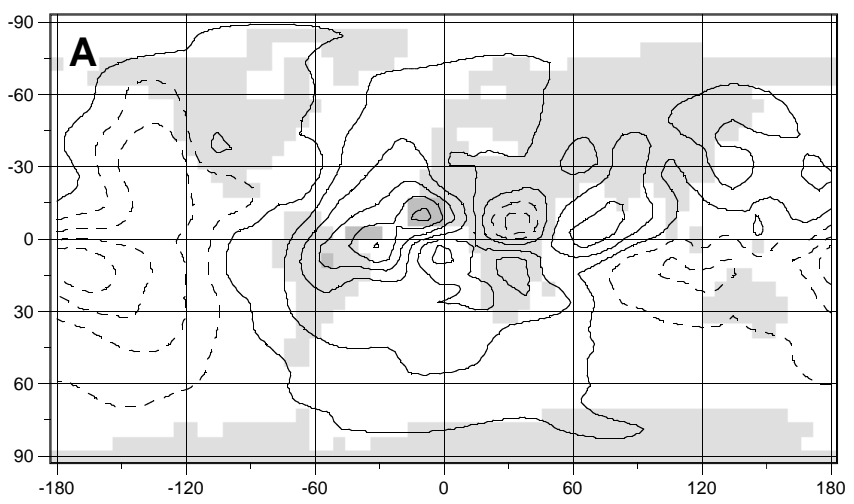

June-August

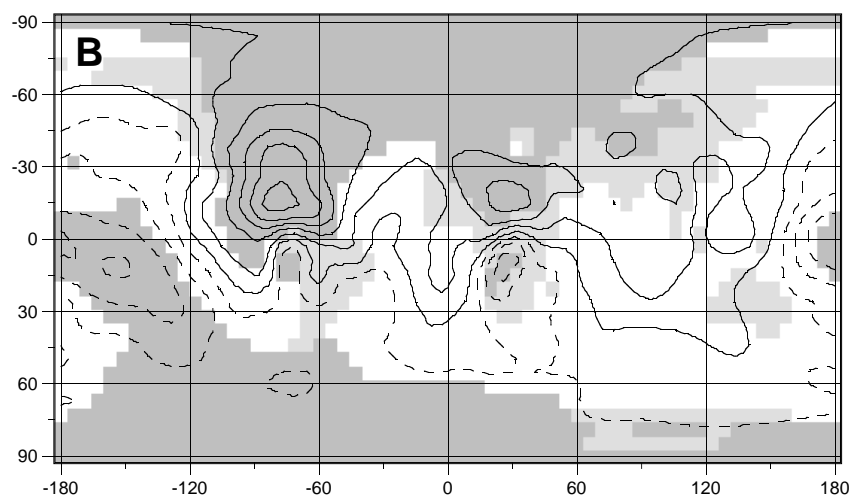

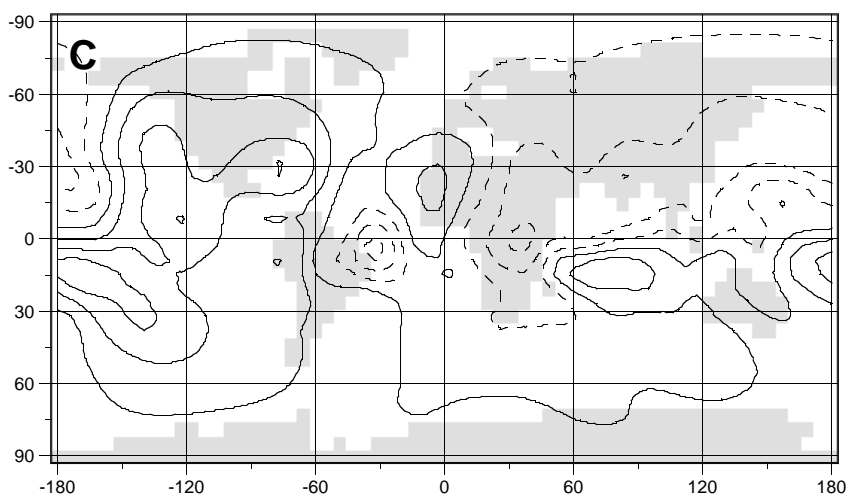

Fig. 4A-D Mean seasonal changes in convergence in divergent wind flow $\mathbf{A}, \mathbf{B}$ at the $850 \mathrm{hPa}$ level and $\mathbf{C}, \mathbf{D}$ at the $200 \mathrm{hPa}$ level for the December-February (left) and June-August (right) season respectively. Solid (dashed) contour lines denote positive (negative) changes.

surface $(2 \mathrm{~m}$ ) air temperatures (of up to $4 \mathrm{~K}$ on the seasonal average and up to $8 \mathrm{~K}$ on a monthly basis) are found for the respective dry-seasons (Fig. 3C, D). The patterns of increases in dry-season evapotranspiration and decreases in near-surface air temperatures correspond very well. Apart from this direct effect, some changes (e.g., in temperature) can be found over the extratropics, on the Northern Hemisphere mainly during DJF and on the Southern Hemisphere mainly during JJA.

The increase in evapotranspiration during the dry season also leads to a consistent increase in atmospheric moisture over the affected region (not shown) and to enhanced moisture transport toward the Inner Tropical Convergence Zone (ITCZ). Thus, more energy is available in the ITCZ in form of latent heat, which then enhances convection and the mean cloud cover in the ITCZ (not shown). As a consequence, longwave radiation at the top-of-the-atmosphere is reduced in these regions (not shown) and precipitation is generally enhanced (Fig. 3E, F). Note that this is an interhemispheric effect; the increase in evapotranspira-

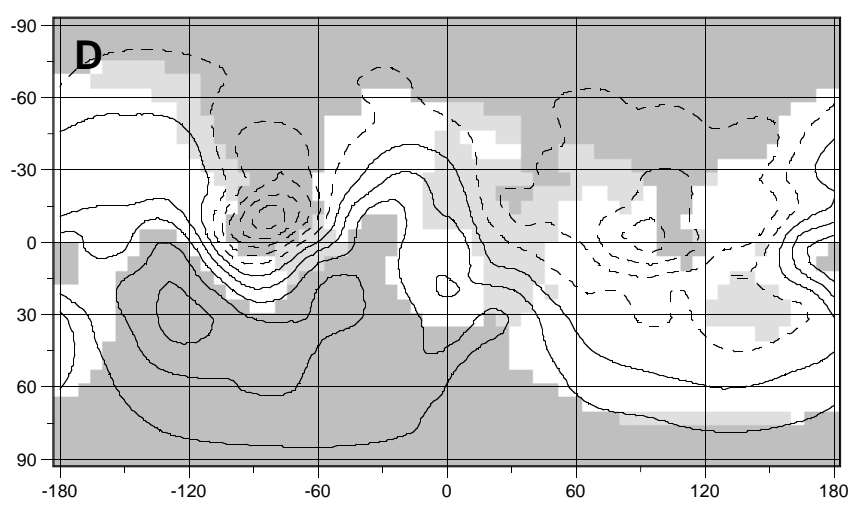

Significant changes are shown in gray (student's $t$-test, $P \leq 0.05$ ). Contour interval is $0.2 \times 10^{6} \mathrm{~m}^{2} / \mathrm{s}$ for $\mathbf{A}, \mathbf{B}$ and $0.4 \times 10^{6} \mathrm{~m}^{2} / \mathrm{s}$ for $\mathbf{C}$, D. Positive changes mean enhanced convergent wind flow. Light gray areas indicate land region in which no significant changes take place

tion during the dry season does in general not lead to enhanced precipitation over the same region but rather on the other hemisphere.

\subsection{Feedback processes}

One positive feedback is illustrated in Fig. 2 which involves the transport of moisture towards the ITCZ: the increased convection is associated with enhanced upward motion in the ITCZ which leads to enhanced wind flow towards the ITCZ. It thus stimulates the general circulation patterns in the tropics (Hadley circulation in the zonal direction and Walker circulation in the meridional direction). The changes in circulation are investigated in terms of changes in the velocity potential near the surface (at the $850 \mathrm{hPa}$ level, Fig. 4A, B) and in the upper atmosphere (at the $200 \mathrm{hPa}$ level, Fig. 4C, D). We notice from Fig. 4 that the wind flow (i.e. the gradient of the velocity potential) is increased towards the convection areas (see Fig. 3E, F) thus providing a positive feedback to further enhance near-surface moisture 
transport towards the ITCZ. This feedback is most pronounced (in terms of absolute magnitude and statistical significance) over South America during the JJA season.

The reduction of solar radiation at the surface in the ITCZ as a consequence of increased cloud cover forms a negative feedback process in that it reduces the net amount of solar energy at the surface. The spatial patterns of change in solar radiation (not shown) are similar to those of the changes in precipiation (Fig. 3E, F, with opposite sign). The reduction in solar radiation at the surface can explain the decrease found in evapotranspiration during the wet periods seen in Fig. 3A, B.

There is also a positive feedback process on an interseasonal time scale: the increases in precipitation during the wet season leads to increased storage of soil water which then further enhances evapotranspiration during the following dry season. This feedback mechanism is mainly found in the semiarid regions of northeastern tropical Africa (not shown).

\section{Comparison to observations}

Are the climatic changes associated with the incorporation of deep roots, especially the strong cooling during the dry seasons, reasonable? We assess this question by different means of observations in the following.

\subsection{Local observations of surface climate}

As observed by Nepstad et al. (1994), the deep roots provide sufficient access to soil water and, as a consequence, the transpiration is maintained throughout the dry season. We demonstrate this effect by showing the seasonal course of evapotranspiration for two model grid cells in South America in Fig. 5A, B. It is evident from Fig. 5, that the incorporation of deep roots leads to a considerable increase of dry season evapotranspiration. The selected grid cells cover two sites where observations in evergreen forest were taken during the ABRACOS project (Gash et al. 1996). While rooting distributions and, consequently, rooting depth were not measured at these sites (although Hodnett et al. 1995, found strong evidence for deep water uptake at these sites), we can get an idea about the reasonability of the seasonal course of evapotranspiration by comparing the simulated near-surface air temperatures to observations. Daily data from automatic weather stations were used to calculate the seasonal course of air temperature and precipitation from a period of up to six years. These measurements can thus be seen as a representative of the "grid box"-scale climate. The seasonal courses of near-surface air temperature show a noticeable improvement when deep roots are used in the model simulation at both sites (Fig. 5C, D). The effect of deep roots within the model does not originate from errors in the model's simulation of precipitation. The simulated length and strength of the dry season, as reflected by dry season precipitation, agrees well with the observations at these sites (Fig. 5E, F) for both simulations, while wet season precipitation is somewhat underestimated. The latent heat flux was also measured at some times during the ABRACOS project. It remained almost constant throughout the dry season similar to our "deep roots" simulation. This kind of behavior is also consistent with observations by Shuttleworth (1988) who found that evapotranspiration from a forest near Manaus did not fall below 10\% of the potential estimate during the dry season. A comparison of solar net radiation at the surface (not shown) reveals that the model somewhat overestimates the seasonality. Considering this, we might expect the evapotranspiration rates during the dry season to be overestimated. This overestimation is nevertheless minor compared to the first order changes resulting from the incorporation of deep roots.

Considerable amounts of evapotranspiration during the dry season was also observed at other sites. Edwards (1979) found in a forest catchment in East Africa, that the forest transpired all year round with roots as deep as $8.2 \mathrm{~m}$ in an area with a 6 months dry period. On an annual basis, actual evapotranspiration was about $90 \%$ of open pan evaporation over several years and evidence for deep soil water uptake was found. On a larger scale, Kreuels et al. (1975) noticed that the Bowen ratio (i.e., the ratio of sensible to latent heat flux) over the evergreen forests of South America was similar to oceanic values, implying that sufficient water was available for evapotranspiration throughout the year. Considering that a seasonal climate exists, these observations also imply that sufficient soil water storages (explored by deep root systems of the vegetation) are available.

\subsection{Seasonal variation of Amazon River basin storage}

Enhanced dry season evapotranspiration in a river basin also leads to an increased seasonal variation in the basinwide storage of water. We compute the seasonal variation of the storage of the Amazon basin (approximated by ten grid cells, taken as $\approx 75^{\circ} \mathrm{W}-55^{\circ} \mathrm{W}, 0^{\circ}-10^{\circ} \mathrm{S}$ and $70^{\circ} \mathrm{W}-60^{\circ} \mathrm{W}, 5^{\circ} \mathrm{N}-0^{\circ}$ ) from the amplitude of the variation in the soil water content and compare it to the seasonal change of the water storage calculated from observations (Matsuyama 1992) in Fig. 6. Note that the exact size of the basin is not crucial since the variations are compared on a unit area basis. It is evident from this comparison, that the incorporation of deep roots into the model leads to a considerable improvement in the variation and the seasonality of basin wide storage. In the standard simulation, the seasonal variation is clearly constrained by the bucket size, while in the simulation with deep roots, the variation is limited by precipitation which is somewhat underestimated during the wet season. The observed variation in soil water 

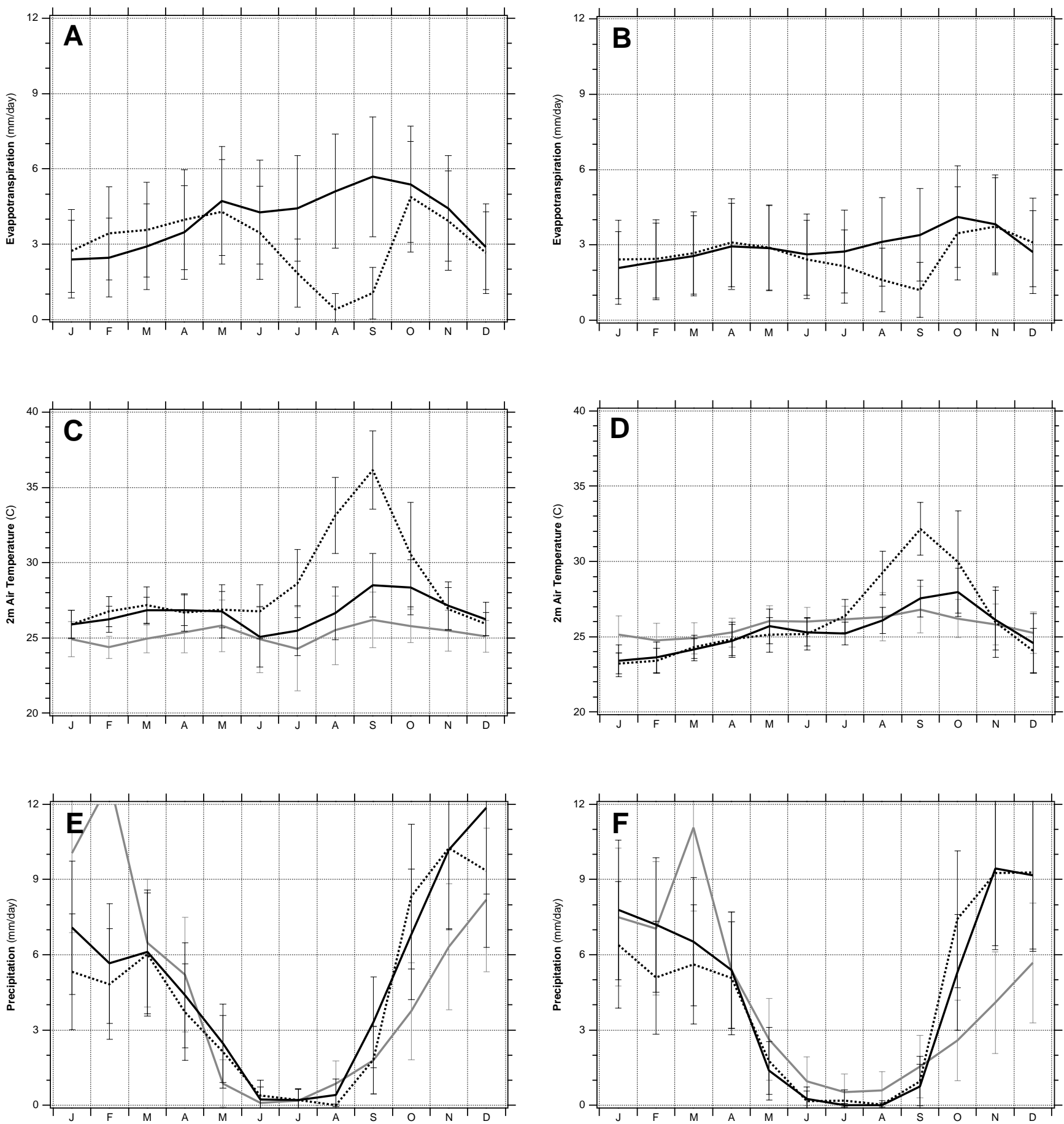

Fig. 5A-F Simulated seasonal course of $\mathbf{A}, \mathbf{B}$ evapotranspiration $\mathbf{C}$, D near surface $(2 \mathrm{~m})$ air temperature and $\mathbf{E}, \mathbf{F}$ precipitation at two grid cells in South America. These grid cells cover two sites at which observations were taken during the ABRACOS project (Gash et al. 1996, left: Ji-Paranà, right: Marabà). The seasonal course of the standard simulation (dotted) and the simulation with deep roots (solid) are shown. Observations of air temperature and precipitation are shown in gray. Error bars indicate one standard deviation. Up to six

depletion by Nepstad et al. (1994) is also of this order ( $\approx 500 \mathrm{~mm}$ ). However, Matsuyama and Masuda (1997) attribute the seasonal variation to flooding and changes in river levels.

years of daily data were used to calculate the seasonal course and the standard deviation for the observations. The meteorological data were collected under the ABRACOS project and made available by the UK Institute of Hydrology and the Instituto Nacional de Pesquisas Espaciais (Brazil). ABRACOS is a collaboration between the Agencia Brasileira de Cooperacao and the UK Overseas Development Administration. The data are available via the Internet by http://yabae.cptec.inpe.br/abracos/available.html

\subsection{Large-scale observations of air temperature}

As a final step, we compare the large-scale seasonal course of air temperature to observations. In order to do 


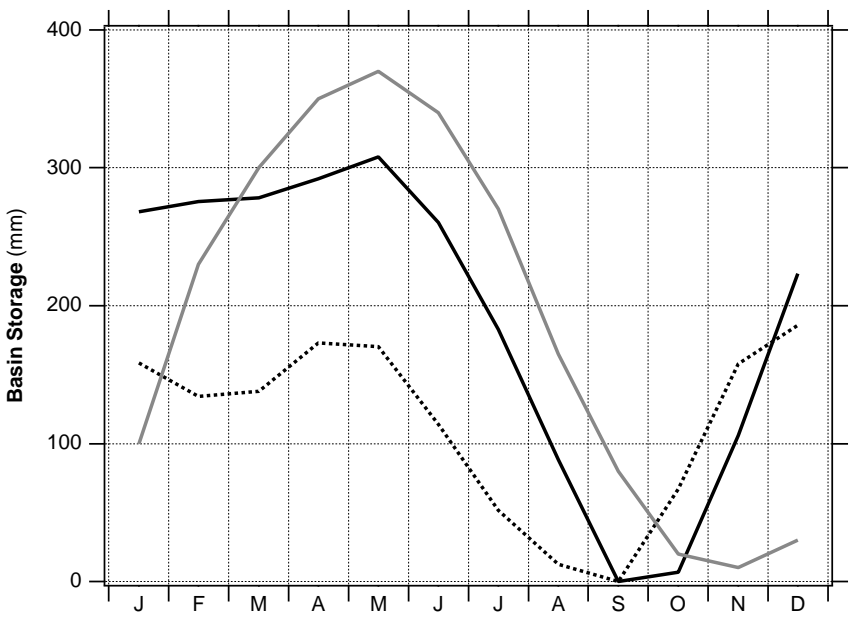

Fig. 6 Seasonal variation of the water storage of the Amazon basin. Shown is the mean seasonal course of the simulation with optimized rooting depths (solid line), with standard rooting depths (dotted line) and observations (gray line, taken from Matsuyama 1992)

so, averages are computed over land for each hemisphere for five regions which cover the areas where the largest changes occur (see also Fig. 3C, D and Fig. 7F). The regions are: northern tropical South America $\left(\approx 0^{\circ}-\right.$ $10^{\circ} \mathrm{N}$, consisting of a total of seven grid cells), southern tropical South America $\left(\approx 0^{\circ}-15^{\circ} \mathrm{S}, 22\right.$ grid cells $)$, northern tropical Africa $\left(\approx 0^{\circ}-15^{\circ} \mathrm{N}, 29\right.$ grid cells $)$, southern tropical Africa $\left(\approx 0^{\circ}-30^{\circ} \mathrm{S}, 21\right.$ grid cells $)$ and Southeast Asia $\left(\approx 0^{\circ}-30^{\circ} \mathrm{N}\right.$, east of $70^{\circ} \mathrm{E}, 25$ grid cells $)$. Tropical Australia is not included in the comparison because the effects are far less pronounced. The seasonal course of near-surface air temperatures of the five regions for the two simulations and for observations (Legates and Willmott 1990) are shown in Fig. 7. The Southern Hemisphere regions of South America (Fig. 7B) and Africa (Fig. 7D) show a clear improvement in the simulation of the seasonal course of air temperature when deep roots are included. The improvement is less in the Northern Hemisphere. In the case of northern tropical Africa (Fig. 7C) temperatures are too low during the dry season compared to observations. This can be attributed to an overestimated strength of the wet season in the simulation leading to exaggerated soil water availability during the dry season. While model biases in the simulation of precipitation and net solar radiation (as the main driving variables) certainly affect the results, these biases are in general minor compared to the first order effect associated with the increased soil water storage.

\section{Application to Amazonian deforestation}

The comparison in the last section showed that the model simulation with deep roots is closer to observations and thus resembles a general improvement of the simulated surface climate. In this section we investigate the role of rooting depth reduction to other parameter changes associated with the large-scale conversion from natural forest to grassland in the context of Amazonian deforestation.

\subsection{Experimental setup}

With the help of four sensitivity simulations we try to assess the relative importance of deep roots and its removal in Amazonia in relation to other surface parameters:

1. In the "shallow roots" simulation, the rooting depth is reduced to $60 \mathrm{~cm}$. This value is translated into maximum soil water storage according to Eq. (4).

2. In the "increased albedo" simulation, only the surface albedo is increased to a value of 0.20 .

3. In the "shallow roots + increased albedo" simulation, both of the changes are incorporated.

4. In the "deforestation" simulation, a whole series of surface parameters is changed to values representing degraded grassland (rooting depth to $60 \mathrm{~cm}$, albedo to 0.20 , vegetation roughness length to $0.08 \mathrm{~m}$, fraction of vegetation cover to 0.85 and leaf area index to 2.2).

The values representing grassland and the region in which these changes take place (see Sect. 4.2) are adapted from Nobre et al. (1991). All simulations run for 20 years with the first five years discarded in order to avoid spin-up effects and are compared to the simulation "deep roots". Fixed climatological sea surface temperatures are used in all simulations. A student's $t$-test is used to estimate the significance of all reported changes $(P \leq 0.10)$.

\subsection{Regional changes}

We investigate the changes of the water fluxes and the atmospheric variables over the deforested area in terms of the seasonal cycle of the regional monthly means for each of the simulations. The annual changes in evapotranspiration, precipitation and near-surface air temperature are summarized in Table 1.

The "shallow roots" simulation clearly shows the effect of the reduced soil water storage (Fig. 8) and is consistent with the results of Sect. 3. The reduced soil water storage capacity leads to reduced dry season evapotranspiration (Fig. 8A), resulting in less atmospheric moisture, less cloud cover and increased solar radiation (Fig. 8E) which is the reversal of the effects found in Sect. 3. Both, the reduction of latent heat flux and the increase in solar radiation lead to an increase in near surface air temperature (Fig. $8 \mathrm{D}$, with $\approx 30 \mathrm{~W} / \mathrm{m}^{2}$ in increase in solar radiation compared to $\approx 90 \mathrm{~W} / \mathrm{m}^{2}$ resulting from the decrease in latent heat flux in August). The increased warming of the surface causes more thermally driven convection counteracting the general subsidence over the region during this period, manifesting itself in lower air pressures (Fig. 8E). The increase in radiative energy (as a result of the reduced 

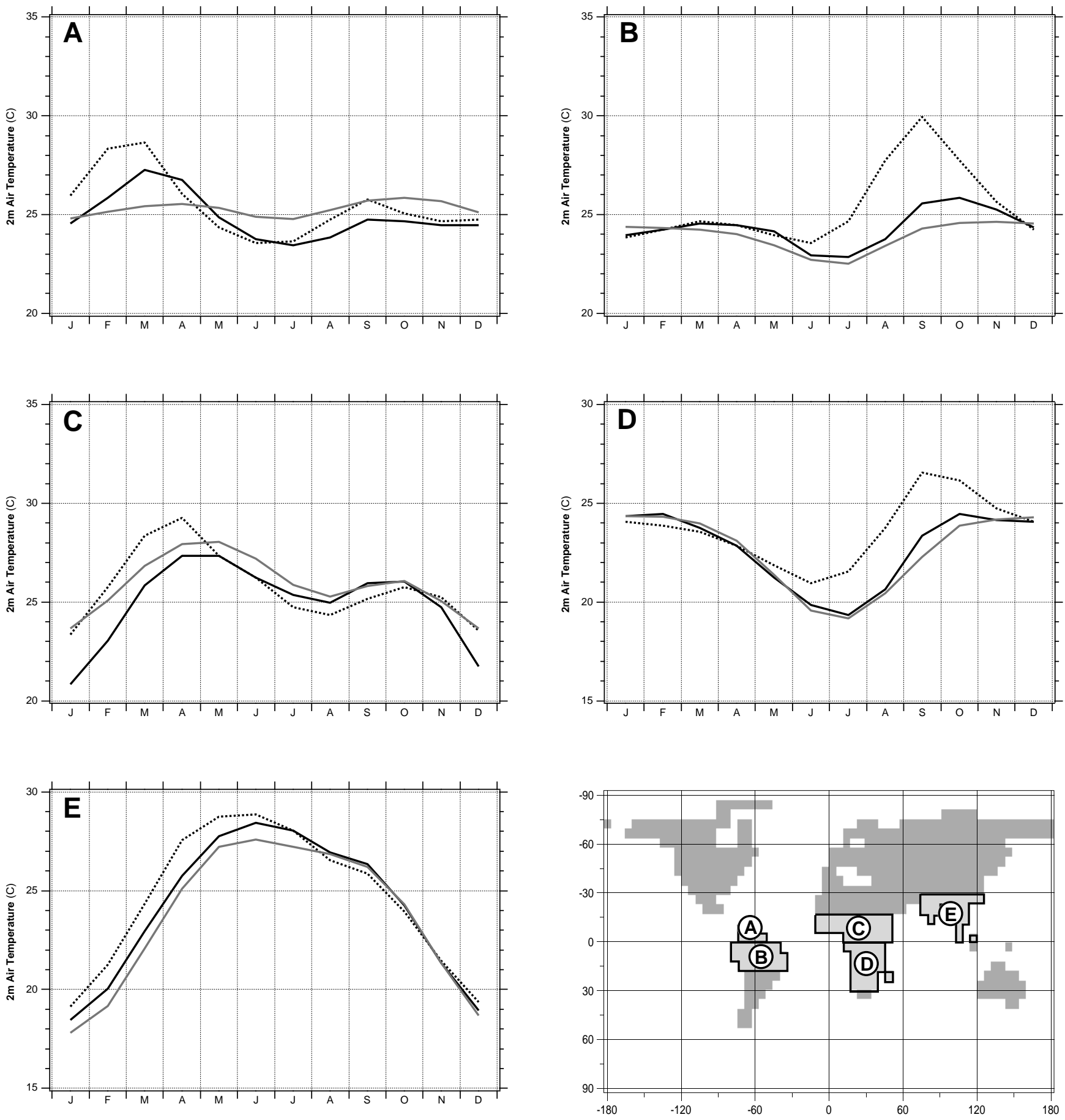

Fig. 7A-E Seasonal course of $2 \mathrm{~m}$ air temperature $\mathbf{A}-\mathbf{E}$ for five different regions (shown in F). The mean seasonal course for the simulation with optimized rooting depths (solid line), with standard

cloud cover) also leads to increased precipitation, mainly during the wet seasons (Fig. 8B). As a result of the changes in evapotranspiration and precipitation, the overall sink of atmospheric moisture is considerably enhanced (Fig. 8C). The seasonal source of moisture (that is, evapotranspiration minus precipitation) during the Southern Hemisphere dry season is completely diminished since the soil is not capable of holding signi-

rooting depths (dotted line) and observations (gray line, Legates and Willmott 1990) are shown

ficant amounts of water which could be recycled by the vegetation. During this time, evapotranspiration is primarily given by the atmospheric input in form of precipitation. The increase in the sink of atmospheric moisture is also associated with a considerable increase in runoff and drainage, so that the mean discharge of the basin is increased by $333 \mathrm{~mm}$ on an annual basis (Table 1). 
Table 1 Annual mean changes of the simulations averaged over the deforested region and comparison to the results of some recent studies. Note that in some studies, the temperature change refers to surface temperature change or surface soil temperature change

\begin{tabular}{|c|c|c|c|c|}
\hline Simulation & $\begin{array}{l}\Delta T \\
\left({ }^{\circ} \mathrm{C}\right)\end{array}$ & $\begin{array}{l}\Delta P \\
(\mathrm{~mm})\end{array}$ & $\begin{array}{l}\Delta E \\
(\mathrm{~mm})\end{array}$ & $\begin{array}{l}\text { Change } \\
\text { moisture } \\
\text { sink }\end{array}$ \\
\hline Shallow roots & +2.5 & +50 & -383 & + \\
\hline Increased albedo & 0.0 & -194 & -106 & - \\
\hline $\begin{array}{l}\text { Shallow roots } \\
+ \text { increased albedo }\end{array}$ & +2.6 & -177 & -495 & + \\
\hline Deforestation & +2.5 & -140 & -474 & + \\
\hline \multicolumn{5}{|l|}{ Other studies } \\
\hline $\begin{array}{l}\text { Henderson-Sellers } \\
\text { and Gornitz (1984) }\end{array}$ & 0.0 & -216 & -162 & - \\
\hline Nobre et al. (1991) & +2.5 & -643 & -496 & - \\
\hline $\begin{array}{l}\text { Dickinson and } \\
\text { Kennedy (1992) }\end{array}$ & +0.6 & -504 & -252 & - \\
\hline $\begin{array}{l}\text { Henderson-Sellers } \\
\text { et al. (1993) }\end{array}$ & +0.6 & -588 & -232 & - \\
\hline $\begin{array}{l}\text { Polcher and Laval (1994) } \\
\text { Dirmeyer and Shukla } \\
\text { (1994) }\end{array}$ & -0.1 & -186 & -128 & - \\
\hline No albedo increase & +2.0 & +83 & -76 & + \\
\hline Albedo increase by 0.06 & +2.0 & -101 & -119 & - \\
\hline Albedo increase by 0.09 & +2.0 & -245 & -137 & - \\
\hline Zhang et al. (1996a) & +0.3 & -403 & -223 & - \\
\hline Sud et al. (1996) & +2.0 & -540 & -445 & - \\
\hline $\begin{array}{l}\text { Hahmann and } \\
\text { Dickinson (1997) }\end{array}$ & +1.0 & -363 & -149 & - \\
\hline Lean and Rowntree (1997) & & & & \\
\hline Increased albedo only & -0.1 & -166 & -50 & - \\
\hline Deforestation & +2.3 & -157 & -296 & + \\
\hline
\end{tabular}

In the "increased albedo" simulation, we find a uniform reduction of surface solar radiation during most parts of the year (Fig. 8E). Since soil water is not limiting (because of the presence of deep roots), primarily the latent heat flux and evapotranspiration are reduced (Fig. 8A) without a change in air temperature (Fig. 8D). The reduced water input into the atmosphere by evapotranspiration cause reduced cloud cover resulting in increased solar radiation at the surface (Fig. 8E), partly offsetting the initial effect of albedo increase (a negative feedback, especially in September). Precipitation is reduced (Fig. 8B) as is the overall sink of atmospheric moisture (Fig. 8C and Table 1). Consequently, runoff and soil drainage are reduced leading to decreased overall river basin discharge by $88 \mathrm{~mm}$ (Table 1). Nevertheless, the region remains a source of atmospheric moisture during the Southern Hemisphere dry season as in the control simulation.

When both effects (albedo increase and rooting depth reduction) are included, the changes over the whole region mainly reflect the composite effect of the individual changes resulting from "shallow roots" and "increased albedo". While the changes in evapotranspiration add up (see above, Fig. 8A and Table 1), most other changes in part cancel, for instance, precipitation, moisture source, solar radiation and sea-level pressure (Fig. 8B, $\mathrm{C}, \mathrm{E}, \mathrm{F})$. The response in solar radiation resulting from the positive feedback associated with the shallow roots outcompetes the response to increased albedo, so that in total an overall increase is found. So the combined response is mainly driven by the reduction in rooting depth. The overall impact of all parameter changes is very similar to the response of the combined effect of rooting depth reduction and albedo increase. The effects of reduced roughness length and decreased leaf area index/interception storage do not seem to further contribute substantially to the overall response.

\subsection{Remote changes}

Consistent with the reversal of the mechanism described in Sect. 3 we find changes in the circulation as a result of the reduction in dry season evapotranspiration and remote effects as a consequence of the large-scale conversion of the Amazonian forest to grassland. We focus here on the period of the southern dry season (JuneAugust) where the effects are strongest. In Fig. 9 we show the changes between the "shallow roots" and the "deep roots" simulations. The reduction in dry season evapotranspiration leads to a strong, large-scale seasonal warming over South America (Fig. 9A) and reduced moisture and energy transport towards the Inner Tropical Convergence Zone (ITCZ). There, convection is reduced leading to a reduction in precipitation (Fig. 9B) and to a general weakening of the tropical circulation (Fig. 9C, D). The weakening of the meridional circulation across the Pacific (Walker circulation) results in remote effects over Southeast Asia (reduced precipitation, Fig. 9B, and low level convergence, Fig. 9C). Another predominant remote response includes a large-scale warming over North America (Fig. 9A). While some of the changes are just below the significance level, the patterns for the "shallow roots + increased albedo" and "deforestation" simulation confirm these changes (not shown) which increases our confidence in the significance. Other patterns are also consistently found in these simulations, for instance decreased $2 \mathrm{~m}$ air temperature over Europe, Africa and Australia indicating indirect effects as a response to the circulation changes. In other seasons, significant changes occur as well, e.g. during December-February where we find a lowering of the Aleutian low pressure system and a general warming over North America (not shown).

\subsection{The effects of moderate parameter changes}

The basic assumption of a large-scale complete conversion of tropical evergreen forest into grassland across the whole Amazon basin is surely an exaggeration. Evidently, the outcome of the simulations depends on the choice of the parameter values used to represent grassland in the model simulations. It is therefore interesting to investigate, how sensitive the response of dry-season evapotranspiration (as the main driver of remote effects) is to partial changes in rooting depth and albedo. Since GCM 

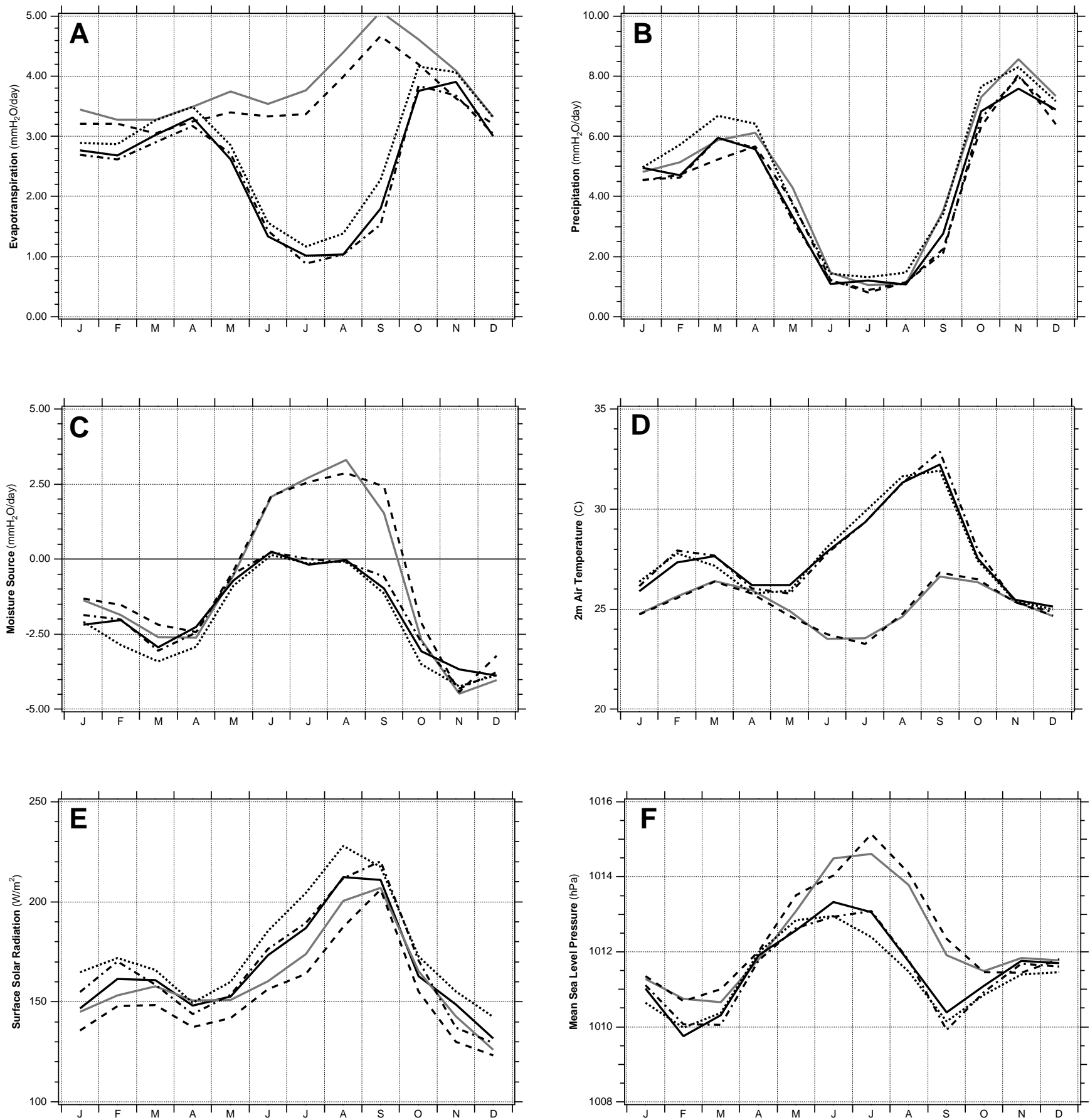

Fig. 8A-F Mean seasonal course of A evapotranspiration, B precipitation, $\mathbf{C}$ moisture source, D $2 \mathrm{~m}$ air temperature, $\mathbf{E}$ net solar radiation at the surface and $\mathbf{F}$ mean sea level pressure averaged over the deforested region. The seasonal course of the simulation with deep

simulations are time consuming, we assess the sensitivity of the evapotranspiration response to the choices made for albedo and rooting depth by a simple budget model. This model simulates evapotranspiration as a function of atmospheric demand and soil water availability.

In this model, evapotranspiration is computed as

$E T=\min [P E T, S]$

roots ("control", gray line), shallow roots (dotted line), increased albedo (dashed line), shallow roots and increased albedo (dot-dashed line) and from the complete deforestation simulation (solid line) are shown

with PET being potential evapotranspiration (or, more precisely, the evapotranspiration rate that would occur in a non-waterlimited environment) and $S$ is the supply rate of the soil for evapotranspiration which is only constrained by the amount of plant available soil water within the rooting zone $W$. For simplicity, the effect of water-stress on evapotranspiration is not considered. The temporal evolution of the soil water content $W$ is 

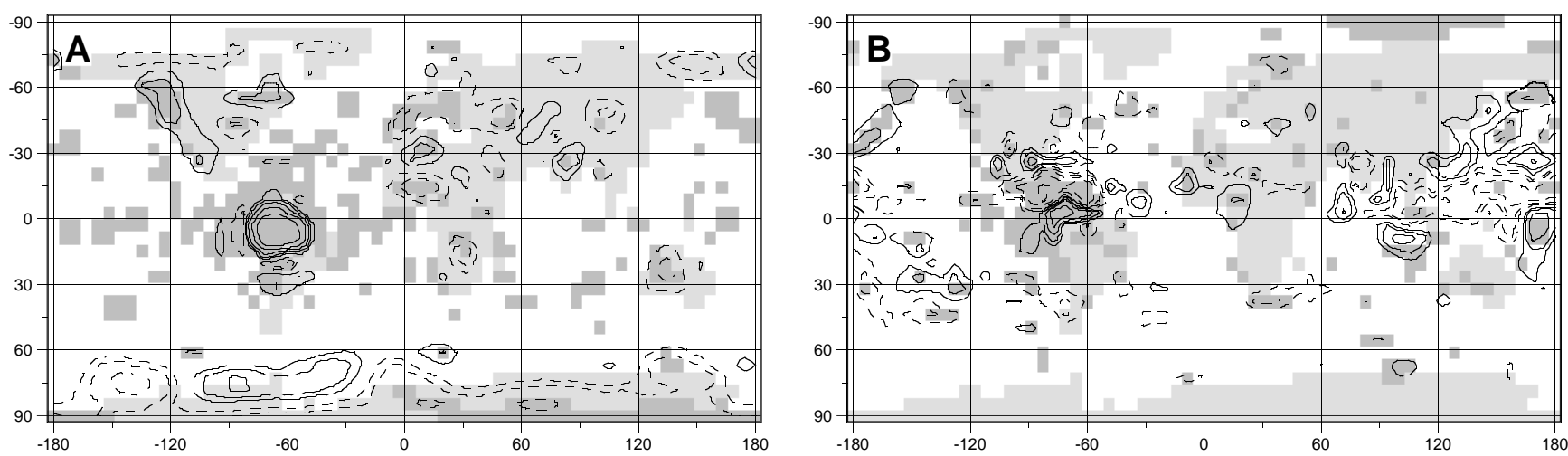

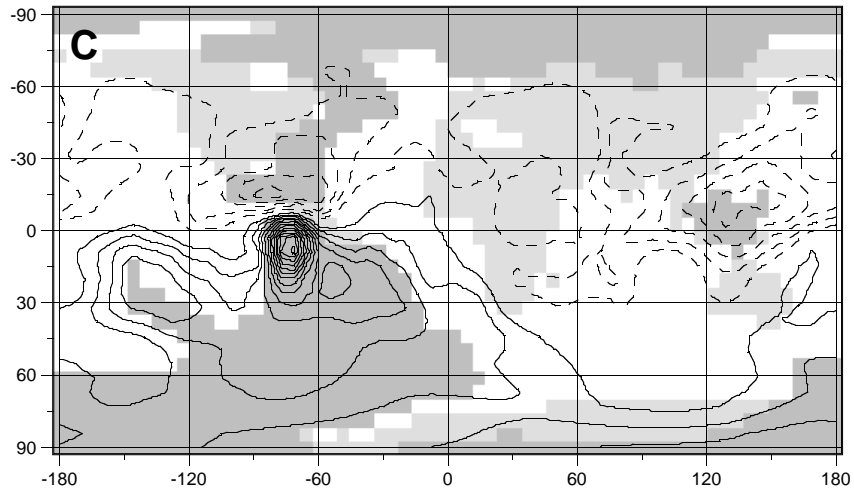

Fig. 9A-D Changes in A $2 \mathrm{~m}$ air temperature, $\mathbf{B}$ precipitation, and $\mathbf{C}$ in velocity potential at $850 \mathrm{hPa}$ level and $\mathbf{D} 200 \mathrm{hPa}$ level during JJA between the "shallow roots" and "deep roots" simulations. Contour interval is $0.25 \mathrm{~K}, 0.25 \mathrm{~mm} /$ day, $0.1 \times 10^{6} \mathrm{~m}^{2} / \mathrm{s}$ and $0.2 \times 10^{6} \mathrm{~m}^{2} / \mathrm{s}$ respectively. Zero lines are omitted. Solid (dashed) contour lines

simulated for plant available water, i.e., between field capacity $F C$ and permanent wilting point $P W P$ ("bucket model"), according to

$W(t+\Delta t)=\min \left[W_{M A X}, W(t)+(P-E T) \Delta t\right]$

where $P$ is the precipitation occurring during the time step $\Delta t$ and $W_{M A X}$ is the bucket size, given by

$W_{M A X}=D \cdot P A W$.

Here, $P A W$ is the maximum plant available water per unit soil depth $(=F C-P W P)$ and $D$ is the rooting depth.

This model runs for each of the deforested grid cells (see Sect. 5.1) on a daily time step in order to integrate Eq. (8). The forcing consists of interpolated mean monthly values of precipitation and evapotranspiration (taken as $P E T$ ) from the "deep roots" simulation of the GCM. The values of $P A W$ are identical to the ones used in the GCM simulation (based on Batjes 1996). While modified rooting depth directly affects Eq. (9) and consequently the simulation of $W$, the effect of modified albedo $a^{\prime}$ is incorporated by changing PET to PET', given by

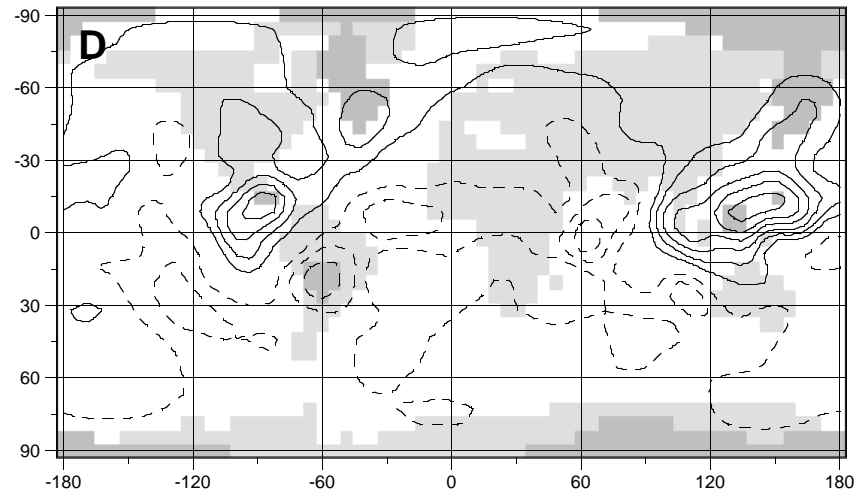

denote positive (negative) changes. Significant changes are shown in gray (student's $t$-test, $P \leq 0.1$ ). Note that sea surface temperatures are prescribed to their climatological values. Light gray areas indicate land region in which no significant changes take place

$P E T^{\prime}=\frac{1-a^{\prime}}{1-a} \cdot P E T$

with $a$ being the albedo of the control simulation. The underlying assumption in Eq. (10) is that the change in net radiation associated with a different albedo directly affects PET.

The response for evapotranspiration is computed with the offline model for a series of more moderate parameter changes. Note that this model does not include the feedback mechanisms described in the previous sections. The simple model is nevertheless capable of capturing the basic features of the seasonal changes associated with rooting depth and albedo change (Fig. 10A, C). The magnitude of change is underestimated (compare extreme values in Fig. 10B, D to those in Table 1) because the feedbacks are neglected (especially solar radiation and precipitation).

When rooting depth is reduced uniformly across the basin from the mean value in the "deep roots" simulation of $9.8 \mathrm{~m}$ down to $0.6 \mathrm{~m}$, the decrease in annual evapotranspiration is first fairly small (Fig. 10B). This can be attributed to the heterogeneity of plant-available 

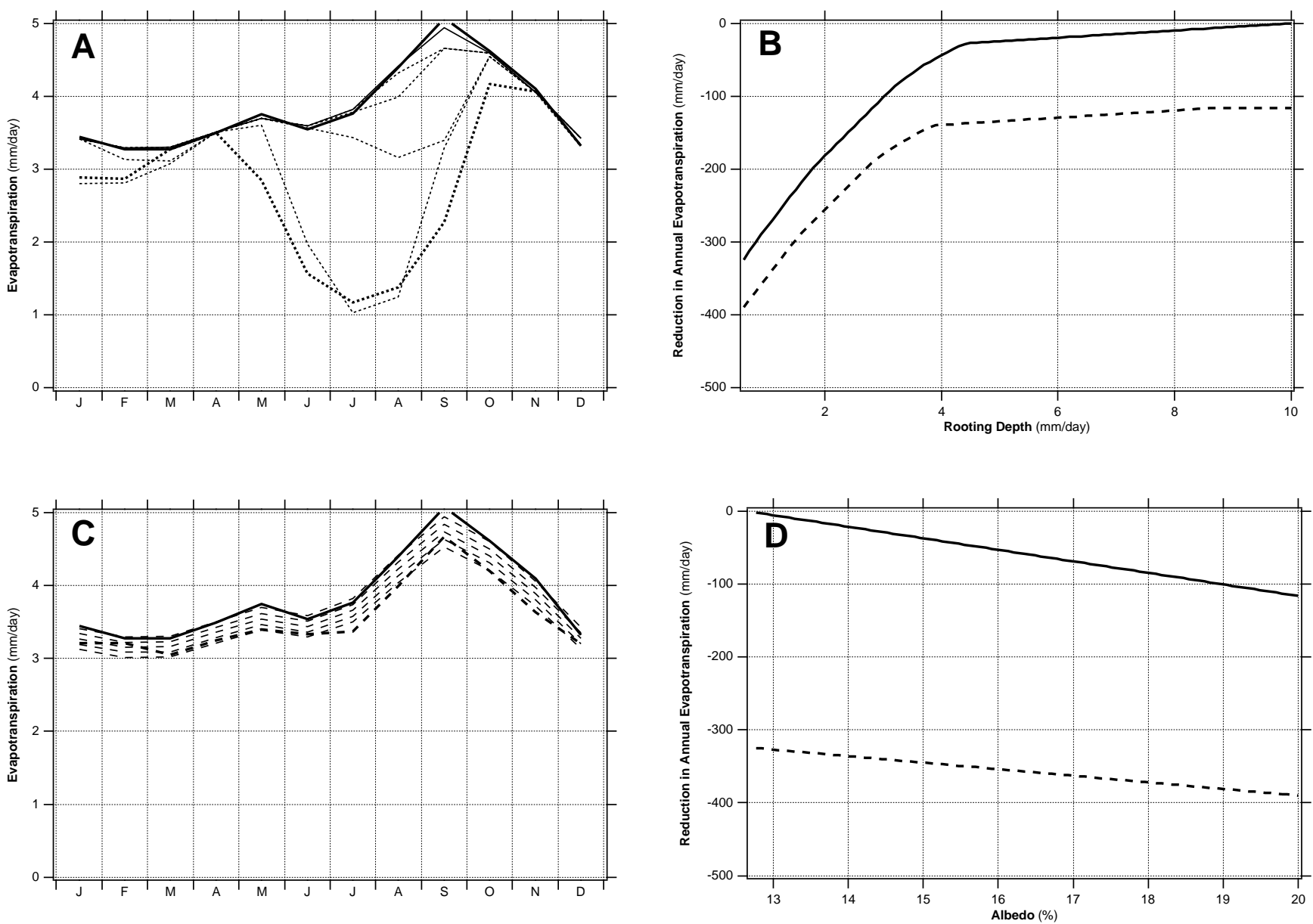

Fig. 10A-D Offline simulation results for regional evapotranspiration with different parameter changes. The seasonal course of evapotranspiration for different values of rooting depth (albedo) is shown in $\mathbf{A}$ and $\mathbf{C}$ (thin lines, with values of $0.6 \mathrm{~m}, 20 \%$, indicate strongest reduction, $2.9 \mathrm{~m}, 18.2 \%, 5.2 \mathrm{~m}, 16.3 \%, 7.5 \mathrm{~m}, 14.5 \%, 9.8 \mathrm{~m}, 12.7 \%$, indicate no reduction, almost identical to the control simulation). The

water which ranges from $50 \mathrm{~mm} / \mathrm{m}$ to $120 \mathrm{~mm} / \mathrm{m}$ across the basin, so that water limitation sets in at different times and different slopes (see also Eq. 9). From a rooting depth of about $4.5 \mathrm{~m}$ downwards, annual evapotranspiration is reduced considerably stronger, and this change takes place during the dry seasons (Fig. 10A). From this point onwards, water limitation sets in for extended periods across the basin. In fact, this critical value represents roughly the annual mean variation in soil water, and is in the order of the reported value of Nepstad et al. (1994). At this lower end, the reduction in annual evapotranspiration is equal to the further decrease in plant available water storage. The start of stronger reduction and the slope might change with added degree of climatic variability. Using a higher albedo, the sensitivity of evapotranspiration to rooting depth is slightly decreased from $325 \mathrm{~mm}$ to $275 \mathrm{~mm}$.

When albedo is increased uniformly across the basin, the mean reduction in annual evapotranspiration is directly proportional to the albedo change (Fig. 10D)

simulations of the GCM are shown in thick lines for comparison (solid: control simulation, dotted in A: shallow roots simulation, dashed in $\mathbf{C}$ : increased albedo simulation). The annual reduction of regional evapotranspiration as a function of rooting depth (with an albedo of $12.7 \%$, solid, and $20 \%$, dashed) and albedo (with a rooting depth of $9.8 \mathrm{~m}$, solid, and $0.6 \mathrm{~m}$, dashed) is shown in $\mathbf{B}, \mathbf{D}$, respectively

which is not surprising considering the way of how the albedo change is incorporated (see Eq. 10). The annual reduction occurs fairly uniformly throughout the year (Fig. 10C). When a shallower rooting depth is used, the slope (and the total sensitivity) decreases from $115 \mathrm{~mm}$ to $75 \mathrm{~mm}$ over the albedo range.

These results stress the importance of soil water storage (and deep roots), which directly affects dry-season evapotranspiration. Any reduction in basin wide soil water storage will lead to some decrease in evapotranspiration and thus favor some remote impacts by the mechanism described. In both cases, the overall sensitivity of the parameter decreases only slightly when the other parameter is modified. This can be explained by the opposing dry and wet seasons across the basin. In the presence of small soil water storages (i.e., shallow roots), the effect of albedo on evapotranspiration primarily occurs in the wet-season regions. Nevertheless, this decrease also contributes to the total, basinwide reduction in evapotranspiration during the Southern Hemisphere dry season. 


\section{Discussion}

In this section we focus on discussing the main two results from this study: first, that the soil moisture availability for transpiration in the tropics is underestimated in the standard model simulation for the present-day climate as a consequence of neglecting the presence of deep rooted vegetation (and consequently the total plant-available soil water storage capacity) and second, that the sensitivity to rooting depth change is also underestimated. Our results are certainly limited to some extend by the method and model used. For instance, physical limitations such as bedrock, permafrost or a permanent water table could restrict the extent of a root system. For a more detailed discussion on the limitation of the method and its implementation we may refer the reader to Kleidon and Heimann (1998a, b). In the following, we examine whether other factors or processes could lead to the same effects, that is, the enhanced dry season evapotranspiration, and the correctness of the sensitivity to rooting depth changes. We also include a comparison to other studies to assess how reasonable the results are.

\subsection{Rooting depths in the present-day climate}

We claim that the rooting depths were underestimated in the standard simulation and that the simulation of present-day climate improved when larger rooting depths are used in the tropics. This is substantiated by the comparison conducted in Sect. 4. However, other aspects could lead to the same climatic changes (note though that the pronounced seasonal signal is distinctively different from the effect of other surface parameters such as albedo or roughness length).

\subsubsection{Factors determining the soil water storage capacity}

The parameter that affects the model's simulation of water stress (and consequently leads to the climatic changes reported in Sect. 3) is the total soil water storage capacity $(S W C)$. Since this parameter is affected by the combination of rooting depth $D$ and plant-available water $P A W$ (see Eqs. 4, 5), the same results could be obtained by a larger value of $P A W$ rather than by deeper roots. However, evidence of local observations of soil texture suggest, that the values of $P A W$ for the highly weathered tropical soils are commonly overestimated. This overestimation is also present in the soil texture used in the standard model (see Sect. 2). For instance, plant available water in the standard model in the Amazon basin are on average about $240 \mathrm{~mm} / \mathrm{m}$ while observed values are generally lower and as low as $30 \mathrm{~mm}$ (Hodnett et al. 1995; Batjes 1996). Because of these low values of $P A W$, the development of a deep root system seems mandatory for evergreen vegetation to survive the dry season but also stresses the importance of accurate soil texture information.

\subsubsection{Evapotranspiration from other sources}

Most evidence for the importance of deep roots in the comparison section originates from the changes due to the increase in evapotranspiration during the dry season. In principle, other processes could contribute to evapotranspiration as well, for instance, evaporation from open water surfaces such as rivers, lakes or wetlands (which was suggested by Matsuyama and Masuda 1997, in the case of the Amazon basin). Since open water bodies only cover a small fraction of the total land area in most regions (Matsuyama and Masuda 1997, cite a value of $7 \%$ maximum inundation for the Brazilian part of Amazonia), they are likely to be able to account for only a small part of the total evapotranspiration flux of a large region (especially in the humid tropics) and their impact consequently appears minor. Another way of assessing the quality of the hydrological changes associated with the presence of deep roots would be to compare the seasonal course of large river basin discharge to observations (see e.g., Hagemann and Dümenil 1997). However, because of the low spatial resolution used here, we did not conduct this comparison.

\subsubsection{Other possible sources of errors}

The strong response to soil water storage and evapotranspiration could in principle originate from errors in the climate model. However, the patterns of change which we found are similar to those obtained in sensitivity studies (e.g., Shukla and Mintz 1982, for evapotranspiration, Milly and Dunne 1994, for soil water storage capacity).

The simulation with the deep roots can be seen as one where the vegetation makes optimum use of water. Even though the vegetation's productivity was optimized in the derivation of rooting depth instead of transpiration, the outcome is close to a maximization of evapotranspiration. The complete removal of water stress is certainly an exaggeration which is likely the consequence of the fairly simple formulation in the model. This behavior is nevertheless much more consistent with observations than a strong reduction of transpiration in the absence of deep roots as it is the case in the standard model. The optimization also leads to the limits that evapotranspiration is controlled by radiation in humid environments and by precipitation in arid ones. It is interesting to note that Budyko (1974) established these limits for annual estimates of evapotranspiration. In this sense, the use of optimized rooting depths is a logical extension to shorter time scales of Budyko's work.

A remaining, more fundamental question is whether observed values of rooting depth can be directly 
translated into soil storage of plant-available water, or if the total water uptake capability needs to be weighted by root biomass density as it is commonly done in models which use multiple soil layers. In the soil hydrology model of the GCM used in this study, no explicit assumption is made of how water uptake by roots is connected to root biomass. This model is nevertheless capable of adequately simulating the regional aspects of surface climate and hydrology when the large soil water storages are used. This could mean that the presence of roots is more important than their quantity, probably because of other processes such as hydraulic lift by plant roots (see e.g., Caldwell et al. 1998) which are less well understood. The implication of this is that the effects seen here should remain even if a more sophisticated land surface scheme were used. Ultimately, it is the net amount of soil water accessible to plants which is underestimated in the standard simulation.

\subsection{Climatic sensitivity to rooting depth changes}

The climatic effects of Amazonian deforestation presented in the last section are a consequence of an increased climatic sensitivity to rooting depth changes. Two factors lead to the increased sensitivity: first, larger values of rooting depth are used in the simulation of present-day climate and second, lower $P A W$ values (which are presumably more realistic) are used in addition with reduced rooting depths for the computation of the $S W C$ s in the sensitivity simulations of the deforested landscape. Note that the lower $P A W$ values do not have an effect on the present-day simulation since the rooting depths were obtained by the optimization method and are therefore adjusted to the lower values. This increased climatic sensitivity to rooting depth changes results in climatic changes which are quite different to most other studies which we explore in the following.

\subsubsection{Comparison to other studies - regional changes}

The climatic effects of Amazonian deforestation explored in Sect. 5 can mainly be attributed to the reduction in rooting depth. While the effect of albedo increase can be found in the simulations, other parameter modifications (reductions in roughness length and leaf area) hardly show up. This is not surprising since the reduction of soil water storage capacities limit evapotranspiration to an extent to which other parameters cannot much further reduce total evapotranspiration. This response is nevertheless reasonable: for instance, Nepstad et al. (1994) observed that the managed pasture lost all its leaf area during the dry season thus not being able to transpire (the reduction in transpiration should not be seen as a consequence of leaf area loss but rather that the reduction of leaf area reflects the soil water status which in turn is likely the result of a shallow rooting depth). As a consequence, the sink of atmospheric moisture increases (Table 1).

\subsubsection{Comparison rooting depth versus albedo change}

We found that most of the changes resulting from the rooting depth reduction counteract the albedo increase. The competing effect of albedo increase to other parameter changes (in our case rooting depth reduction) is consistent with the findings of Dirmeyer and Shukla (1994). They found in a deforestation simulation in which albedo was not changed an increase in precipitation and overall moisture sink over the deforested region as in the "shallow roots" simulation (see also Table 1) which they attributed to the same mechanism (i.e., reduced cloud cover). This competing effect is not surprising: after all, the surface albedo, at least in part, reflects the greenness of the vegetation, which in turn is controlled by the water availability. Thus, in a natural environment changes in albedo and rooting depth do not occur independently from each other. It is rather the difference in ecological survival strategy between evergreen forest and grassland which leads to the changes in the surface parameters. In the case of the evergreen forest, the low albedo reflects the sufficient water availability (and the ability to maintain deep root systems) while grasslands naturally "risk" the disadvantages of periods of water stress, reflected in their shallow dense rooting systems. For grasses, a higher albedo (and consequently less evaporative demand) is beneficial for their survival strategy.

\subsubsection{Comparison to other studies - remote changes}

A few studies, in which all tropical evergreen forests were replaced, investigated global effects of deforestation (McGuffie et al. 1995; Zhang et al. 1996b; Sud et al. 1996). The results reported here differ in two aspects: first, surface parameters were modified in Amazonia only, and can therefore be attributed to originate from this particular region (and the reduction in rooting depth only). Second, the overall response is opposite to most studies, that is, we find an increase in radiative forcing over Amazonia despite the albedo increase as a result of a cloud feedback process. Nonetheless, we attributed most of the remote changes not to the changes in radiation over the deforested area but rather to the reduced evapotranspiration (and moisture export) during the Southern Hemisphere dry season.

\section{Summary and conclusion}

We showed that the consideration of larger rooting depths (and consequently larger soil water storage capacities) in a climate model leads to an improved simulated present-day climate. Deep rooted vegetation acts as a large water capacitor leveling out seasonality in evapotranspiration in seasonal environments in the tropics by the ability of greater access to water stored in the soil. In this sense, the inclusion of deep roots 
makes a land surface appear more like an ocean surface in terms of its evaporative behavior emphasizing the importance of vegetation in land surface functioning. The local consequence is little warming (on a monthly mean basis) during the dry season, which is not expected from the seasonality of precipitation and solar radiation. The persistence of evapotranspiration during the dry season is associated with an increased energy transfer in the form of latent heat towards the inner tropical convergence zone, where convection is generally enhanced and the overall tropical circulation patterns are strengthened. Since it is the net storage of soil water accessible to the vegetation which is underestimated in the standard model it seems that the effects found in this study should be fairly model independent. Especially the (non)seasonality of near surface air temperature in the tropics appears to be a strong indicator for sufficient water availability during the dry season and thus for the presence of deep rooted vegetation on a large scale. We may therefore conclude that deep rooted vegetation is an important component of the tropical climate system and may suggest that larger rooting depths should be used in the tropics within other climate models.

We also found that the total climatic response resulting from large-scale Amazonian deforestation can be attributed mainly to the reduction in rooting depth as a result of the increased climatic sensitivity to rooting depth change. On a regional level, the effect of increased albedo is overruled by a cloud feedback process initiated by the strong reduction in dry-season evapotranspiration caused by the shallow rooting depths. We also detected some significant remote impacts which are similar to those occurring during an El-Niño/Southern Oscillation (ENSO) warm phase. These can be explained by the reversal of the mechanism outlined. This, again, emphasizes the important role of deep rooted vegetation in the tropics.

We consider this work as a first step towards a more realistic representation of vegetation behavior in a climate model. However, more observations are needed for comparison in order to be more confident about the model's prediction in the simulated regional-scale behavior of evapotranspiration (and its relation to rooting properties), but also about the importance of dry season evapotranspiration from land areas as a source of energy for the ITCZ. The large scale biosphere-atmosphere experiment in Amazonia (LBA) is an ideal project for gathering this sort of data on the appropriate scales. We hope that the results of this project will provide additional means of testing the proposed mechanism.

We can raise additional, more fundamental questions from the results of this study. Considering that the inclusion of the optimized rooting depths lead to a general improvement of the simulated surface climate, we may also conclude that the vegetation in large areas does indeed act, at least near, the optimum. Do other vegetation parameters (such as albedo) also reflect optimum adaptation to the environment? What are the requirements (e.g., biodiversity) and limitations (e.g., disturbance such as fire) for this optimum behavior? Assessing these questions may lead to a better understanding of the interaction between climate and ecosystems in general and the effects of human influence by changing ecosystems in particular.

Acknowledgements We would like to thank the German Climate Computing Centre (DKRZ) for providing the computing environment which we used for conducting the simulations. We are also grateful to the reviewers for their critical comments on the manuscript. This research contributes to the Global Change and Terrestrial Ecosystems (GCTE) core project of the International Geosphere Biosphere Programme (IGBP).

\section{References}

Batjes NH (1996) Development of a world data set of soil water retention properties using pedotransfer rules. Geoderma 71: 3152

Budyko MI (1974) Climate and life. Translated from the original Russian edition. Academic Press, New York

Caldwell MM, Dawson TE, Richards JH (1998) Hydraulic lift: consequences of water efflux from the roots of plants. Oecologia 113: 151-161

Canadell J, Jackson RB, Ehleringer JR, Mooney HA, Sala OE, Schulze ED (1996) Maximum rooting depth of vegetation types at the global scale. Oecologia 108(4): 583-595

Chauvel A, Grimaldi M, Tessier D (1991) Changes in soil porespace distribution following deforestation and revegetation: an example from the central Amazon Basin, Brazil. For Ecol Manage 38: 259-271

Dickinson RE, Kennedy P (1992) Impacts on regional climate of Amazonian deforestation. Geophys Res Lett 19(19): 1947-1950

Dickinson RE, Henderson-Sellers A, Kennedy PJ (1993) Biosphere-Atmosphere Transfer Scheme (BATS) Version 1e as coupled to the NCAR Community Climate Model. NCAR/TN387, National Center for Atmospheric Research, Boulder, Colorado, USA

Dirmeyer PA, Shukla J (1994) Albedo as a modulator of climate response to tropical deforestation. J Geophys Res 99(D10): $20863-20877$

Dümenil L, Todini E (1992) A rainfall-runoff scheme for use in the Hamburg climate model. In: Kane $\mathbf{J}$ (ed) Advances in theoretical hydrology - a tribute to James Dooge. Elseviers Science, Amsterdam pp 129-157

Edwards KA (1979) The water balance of the Mbeya experimental catchment. East Afr Ag Fores J, Spec Iss: 231-247

Gash JHC, Nobre CA, Roberts JM, Victoria RL (1996) Amazonian deforestation and climate. John Wiley, Chichester

Hagemann S, Dümenil L (1997) A parametrization of the lateral waterflow for the global scale. Clim Dyn 14(1): 17-31

Hahmann AN, Dickinson RE (1997) RCCM2-BATS model over tropical South America: applications to tropical deforestation. J Clim 10: 1944-1964

Heimann M, Keeling CD (1989) A three-dimensional model of atmospheric $\mathrm{CO}_{2}$ transport based on observed winds: 2 . Model description and simulated tracer experiments. AGU Monogr 55: $237-275$

Henderson-Sellers A, Gornitz V (1984) Possible climatic impacts of land cover transformations, with particular emphasis on tropical deforestation. Clim Change 6: 231-257

Henderson-Sellers A, Dickinson RE, Durbridge TB, Kennedy PJ, McGuffie K, Pitman AJ (1993) Tropical deforestration: modeling local- to regional-scale climate change. J Geophys Res 98(D4): 7289-7315

Hodnett MG, Pimentel da Silva L, da Rocha HR, Cruz Senna R (1995) Seasonal soil water storage changes beneath central Amazonian rainforest and pasture. J Hydrol 170: 233-254 
Kleidon A, Heimann M (1998a) A method of determining rooting depth from a terrestrial biosphere model and its impacts on the global water- and carbon cycle. Global Change Biol 4(3): 175-186

Kleidon A, Heimann M (1998b) Optimised rooting depth and its impacts on the simulated climate of an atmospheric general circulation model. Geophys Res Lett 25(3): 345-348

Knorr W (1997) Satellitengestützte Fernerkundung und Modellierung des globalen $\mathrm{CO}_{2}$-Austauschs der Landvegetation: Versuch einer Synthese. PhD Thesis, University of Hamburg: 193 pp. available in English via http://www.mpimet.mpg.de/ gbc/wolfgang/index.html

Kreuels R, Fraedrich K, Ruprecht E (1975) An aerological climatology of South America. Meteorol Rdsch 28: 17-24

Lean J, Rowntree PR (1997) Understanding the sensitivity of a GCM simulation of Amazonian deforestation to the specification of vegetation and soil characteristics. J Clim 10: 1216-1235

Legates DR, Willmott CJ (1990) Mean seasonal and spatial variability in global surface air temperature. Theor Appl Climatol 41: $11-21$

Matsuyama H (1992) The water budget in the Amazon River Basin during the FGGE period. J Meteorol Soc Japan 70(6): 10711084

Matsuyama H, Masuda K (1997) Estimates of continental-scale soil wetness and comparison with the soil moisture data of Mintz and Serafini. Clim Dyn 13: 681-689

McGuffie K, Henderson-Sellers A, Zhang H, Durbidge TB, Pitman AJ (1995) Global climate sensitivity to tropical deforestation. Global Planet Change 10: 97-128

Milly PCD, Dunne KA (1994) Sensitivity of the global water cycle to the water-holding capacity of land. J Clim 7: 506-526

Monsi M, Saeki T (1953) Über den Lichtfaktor in den Pflanzengesellschaften und seine Bedeutung für die Stoffproduktion. Jap J Bot 14: 22-52

Monteith JL (1977) Climate and the efficiency of crop production in Britain. R Soc London Philos Trans Ser B, 281: 277-294

Nepstad DC, de Carvalho CR, Davidson EA, Jipp PH, Lefebvre PA, Negreiros HG, da Silva ED, Stone TA, Trumbore SE, Vieira $S$ (1994) The role of deep roots in the hydrological and carbon cycles of Amazonian forests and pastures. Nature 372: 666-669

Nobre CA, Sellers PJ, Shukla J (1991) Amazonian deforestation and regional climate change. J Clim 4: 957-988

Patterson KA (1990) Global distributions of total and total-available soil water-holding capacities. University of Delaware, Newark, Del 119 pp
Polcher J, Laval K (1994) A statistical study of the regional impact of deforestation on climate in the LMD GCM. Clim Dyn 10: 205-219

Press WH, Teukolsky SA, Vetterling WT, Flannery BP (1992) Numerical recipes in FORTRAN. In: The art of scientific computing. Cambridge University Press, Cambridge, UK

Roeckner E, Arpe K, Bengtsson L, Christoph M, Claussen M, Dümenil L, Esch M, Giorgetta M, Schlese U, Schulzweida U (1996) The atmospheric general circulation model ECHAM-4: model description and simulation of present-day climate. Max-Planck-Institut für Meteorologie, Hamburg, Germany, Rep 218

Schulze ED (1982) Plant life forms and their carbon, water and nutrient relations. In: Lange OL, Nobel PS, Osmond CB, Ziegler H (eds) Physiological plant ecology II. Springer, Berlin Heidelberg pp 615-676

Sellers PJ, Mintz Y, Sud YC, Dalcher A (1986) A simple biosphere model (Sib) for use within general circulation models. J Atmos Sci 43: 505-531

Sellers PJ, Randall DA, Collatz GJ, Berry JA, Field CB, Dazlich DA, Zhang C, Colello GD, Bounoua L (1996) A revised land surface parametrization (SiB2) for atmospheric GCMs. Part I: model formulation. J Clim 9: 676-705

Shukla J, Mintz Y (1982) The influence of land-surface-evapotranspiration on the earth's climate. Science 247: 13221325

Shuttleworth WJ (1988) Evaporation from Amazonian rainforest. Proc R Soc London B 233: 321-346

Stone EL, Kalisz PJ (1991) On the maximum extent of tree roots. For Ecol Manage 46: 59-102

Sud YC, Walker GK, Kim J-H, Liston GE, Sellers PJ, Lau WK-M (1996) Biogeophysical consequences of a tropical deforestation scenario: a GCM simulation study. J Clim 9: 3225-3247

Tomasella J, Hodnett MG (1996) Soil hydraulic properties and van Genuchten parameters for an oxisol under pasture in central Amazonia Amazonian deforestation and climate. In: Gash JHC, Nobre CA, Roberts JM, Victoria RL (eds) Amazonian deforestation and climate. John Wiley, Chichester pp $101-123$

Zhang H, Henderson-Sellers A, McGuffie K (1996a) Impacts of tropical deforestation. Part I: process analysis of local climatic change. J Clim 9: 1497-1517

Zhang H, McGuffie K, Henderson-Sellers A (1996b) Impacts of tropical deforestation. Part II: the role of large-scale dynamics. J Clim 9: 2498-2521 